\title{
Heparin Induced Thrombocytopenia and Cardiac Surgery: A Comprehensive Review
}

\author{
Jeremy Steele ${ }^{1}$, Bernard Kadosh ${ }^{1}$, losif M. Gulkarov ${ }^{2}$ and Arash Salemi ${ }^{3}$ \\ ${ }^{1}$ Ross University School of Medicine, New York Methodist Hospital, $5066^{\text {th }}$ Street, Brooklyn, New York, 11215 \\ ${ }^{2}$ Department of Cardiothoracic Surgery, New York Methodist Hospital, $5066^{\text {th }}$ Street, Brooklyn, New York 11215 \\ ${ }^{3}$ Department of Cardiothoracic Surgery, New York Presbyterian Hospital-Weill Cornell Medical College, New York, NY
}

\begin{abstract}
Heparin induced thrombocytopenia presents as an underdiagnosed condition with life threatening thrombotic complications. The incidence in cardiac surgery patients is dependent on several factors and appeared to be greater in procedures that involve the use of intraaortic balloon pump. Clinical diagnosis is particularly challenging in cardiac surgery patients due to the natural occurrence of post-operative thrombocytopenia. High index of suspicion is key factor to establish adequate treatment and prevent the occurrence of thrombotic complications, such as saphenous vein graft occlusion, pulmonary embolism and myocardial infarction, which lead to substantially increased mortality rates. The 4T's assessment point system was designed in order to evaluate the likelihood of occurrence of the condition based on clinical presentation; however, serotonin release assay represents the gold standard to reach diagnosis. Treatment of heparin induced thrombocytopenia involves cessation of unfractionated and fractionated heparin, and the instauration of therapy with direct thrombin inhibitors. Among all direct thrombin inhibitors agents, Bivaluridin is emerging as a potential first line of treatment based on its benefits of a short half-life and enzymatic elimination.
\end{abstract}

\section{Introduction}

Heparin induced thrombocytopenia (HIT) is a well recognized complication of heparin therapy and usually occurs within five to ten days after the initiation of heparin treatment [1]. It is important to note the distinction between the two variants of the disease. Type I HIT has an incidence of $10-25 \%$ in all patients receiving heparin treatment and is considered to be of minimal clinical consequence [5]. It is characterized by a fall in platelet count that occurs within days of heparin administration. In type I HIT the platelet count returns to normal and heparin treatment is not discontinued. The mechanism of thrombocytopenia in Type I HIT is non-immune mediated but rather the effect of heparin on platelet activation. For the remainder of this review, the term HIT will refer only to the Type II variant.

HIT is an immune-mediated disorder which is characterized by the formation of antibodies against the heparin-platelet factor 4 (PF4) complex. The incidence of HIT is between 0.2 and $5 \%$ in patients who are exposed to heparin for 4 days or more [6-10]. Several factors increase the risk of development of HIT, highlighted amongst them are the duration of heparin treatment, the use of unfractionated heparin, surgery, and female gender [11-14]. The presence of the heparin-PF4 complex antibodies does not guarantee the presence of the disease. Antibodies are more likely to occur in patients undergoing cardiac surgery, with an antibody incidence reported as high as $15-20 \%$ [1516]. The creation of the HIT antibodies to the PF4/heparin complexes can only occur over a narrow molar ratio of reactants. This implies that high concentrations of heparin, such as those used in cardiopulmonary bypass disrupts antigen formation and prevents the thrombocytopenic episode1. This serves as a reasonable explanation to why the appearance of HIT antibodies is higher in cardiac surgery patients while the clinical appearance of HIT remains lower.

Heparin is a sulphated oligosaccharide and its use for a period of 4 or more days is able to trigger an immune-mediated response. The antibodies formed can be IgG, IgM, or IgA and are not necessarily provoked by heparin alone because the heparin/PF4 complex is highly immunogenic [15-16]. Once platelets are activated with the heparin/ PF4 antibody complex they undergo aggregation and are removed from the circulation. This leads to the development of thrombocytopenia and the appearance of pro-coagulant micro-particles which can result in thrombosis [1-4].

HIT is associated with a fall in platelet count of greater than 50\% and typically presents five to ten days after heparin therapy has been initiated 1 . The thrombocytopenia associated with HIT is generally not considered to be severe, with platelet counts routinely remaining above $20,000 /$ microL and a median of approximately $60,000 /$ micro $[18,19]$. A difficult task is the diagnosis of HIT in patients who have undergone cardiac surgery because in this patient group a major decrease in their platelet count of up to $50 \%$ occurs almost universally within 72 hours of the surgery [20-22]. Risk factors which are associated with an increased incidence of HIT in cardiac surgery patients are renal insufficiency, intravenous application of heparin for more than 3 days, and a recent history of percutaneous coronary intervention [5]. Additionally thrombocytopenia may be maintained in these patients due to reasons unrelated to HIT [24]. Heparin-dependent antibodies are often present in cardiac surgery patients (occasionally reported to be as high as $50 \%$ ), however a secondary fall in platelet count between days five and ten post-operation is highly predictive of HIT [20-22].

Suspecting HIT is the first step in diagnosis of the disease. Aside from the aforementioned drop in platelets other findings that should lead a clinician to suspect HIT are unexplained thrombocytopenia, venous or arterial thrombosis in the presence of thrombocytopenia,

${ }^{*}$ Corresponding author: Arash Salemi, New York Presbyterian Hospital-Weill Cornell Medical College, 525 East 68th Street M-404, New York, New York 10065 Tel: (212) 746-5873; Fax: (212) 746-8388, E-mail: ars9001@med.cornell.edu

Received November 05, 2011; Accepted December 12, 2011; Published December 20, 2011

Citation: Steele J, Kadosh B, Gulkarov IM, Salemi A (2011) Heparin Induced Thrombocytopenia and Cardiac Surgery: A Comprehensive Review. J Blood Disord Transfus S2:003. doi:10.4172/2155-9864.S2-003

Copyright: (C) 2011 Steele J, et al. This is an open-access article distributed under the terms of the Creative Commons Attribution License, which permits unrestricted use, distribution, and reproduction in any medium, provided the original author and source are credited. 


\begin{tabular}{|c|c|c|c|}
\hline Category & 2 Points & 1 Point & 0 Points \\
\hline $\begin{array}{l}\text { Thrombocyto- } \\
\text { penia }\end{array}$ & $\begin{array}{l}>50 \% \text { fall or Nadir } \\
\text { of } 20-100 \times 10^{9} / \mathrm{L}\end{array}$ & $\begin{array}{l}30 \%-50 \% \text { fall or } \\
\text { Nadir of } 10-1^{9} \mathrm{x} \\
109 / \mathrm{L}\end{array}$ & $\begin{array}{l}<30 \% \text { fall or Nadir } \\
\text { of }<10 \times 10^{9} / \mathrm{L}\end{array}$ \\
\hline $\begin{array}{l}\text { Timing of platelet } \\
\text { count fall }\end{array}$ & $\begin{array}{l}\text { Days } 5-10 \text { or less } \\
\text { than or equal } 1 \text { day } \\
\text { if there is heparin } \\
\text { exposure within the } \\
\text { past } 30 \text { days. }\end{array}$ & $\begin{array}{l}\text { Greater than day } \\
10 \text { or unclear or } \\
\text { less than } 1 \text { day if } \\
\text { heparin exposure } \\
\text { within past } 30- \\
100 \text { days }\end{array}$ & $\begin{array}{l}\text { Less than or equal } \\
\text { to } 1 \text { day with no } \\
\text { recent heparin } \\
\text { therapy }\end{array}$ \\
\hline $\begin{array}{l}\text { Thrombosis or } \\
\text { other sequlae }\end{array}$ & $\begin{array}{l}\text { Proven thrombosis, } \\
\text { skin necrosis, or } \\
\text { other heparin bo- } \\
\text { lus, acute systemic } \\
\text { reaction }\end{array}$ & $\begin{array}{l}\text { Progressive, } \\
\text { recurrent, or } \\
\text { silent thrombosis; } \\
\text { erythematous skin } \\
\text { lesions }\end{array}$ & None \\
\hline $\begin{array}{l}\text { Other causes of } \\
\text { thrombocyto- } \\
\text { penia }\end{array}$ & None evident & Possible & Definite \\
\hline
\end{tabular}

Table 1: The 4T's assessment point system.

necrotic skin lesions at heparin injection sites, and acute anaphylactoid reactions after IV boluses of heparin. The difficulty in establishing a clinical diagnosis of HIT was aided by the creation of the 4T's assessment point system [24] (Table 1).

Scores of $0-3$ indicate a low probability of HIT. Scores of $4-5$ represent an intermediate probability and scores of 6-8 represent a high probability of HIT. This scoring system is in place to determine the probability of HIT but is not confirmatory. Currently there are 2 forms of assays in use for diagnosing HIT. The serotonin release assay measures platelet activation and is considered to be the gold standard. It measures the release of $14 \mathrm{C}$-serotonin when therapeutic concentrations of heparin are used. The test has both a high sensitivity and specificity (both between $89-100 \%$ ) with the downside of limited availability and high cost [23]. The second assay are the antigen assays (ELISA) which are severely limited by their inability to distinguish between nonpathogenic and clinically relevant antibodies, their value lies in their high negative predictive value [23].

The most pressing complication with HIT is thrombosis which occurs in both the venous and arterial circulation. The release of procoagulant micro-particles from activated platelets is likely the primary event. In the general population the incidence of thrombotic events that result from HIT is between 30 and 50\% [32,38]. Venous events are 4 times more likely [38]. However, in patients undergoing cardiac surgery the occurrence of arterial thrombosis is equal to that of venous events [23]. Furthermore, the variation in location of thrombotic events as a result of HIT is particularly concerning for physicians. Potential thrombotic complications include renal artery thrombosis, mesenteric ischemia, pulmonary embolus, stroke, and saphenous vein graft occlusion [38]. Ischemia requiring amputation occurs in 5-10\% of cardiac surgery patients who experience arterial thrombotic events [23]. The incidence of thrombotic events correlated heavily with the degree of thrombocytopenia and cardiac surgery patients generally have platelet counts lower than $100,000 / \mu \mathrm{L}$ when thrombotic events occur [36]. The mortality rate in patients with HIT as a result of thrombotic events varies by procedure however procedures requiring an IABP have the highest rate [30]. In patients with peripheral vascular disease undergoing bypass with heparin-bonded grafts, HIT prevents the wound from properly healing and often results in ischemia and necrosis despite graft patency [36].

\section{Management}

Timing is crucial for the successful management of HIT. Cardiac surgical patients who undergo long stays in the intensive care unit are at particular risk for thrombocytopenia from various sources in addition to HIT such as sepsis or mechanical assistance such as aortic counterpulsation [34]. Treatment strategy must be implemented for patients in whom HIT is clinically suspected, while serological tests are used to confirm the diagnosis [31]. One study identified that HIT in perioperative cardiac patients was associated with central venous thrombo-embolism, whereas sepsis, microcirculatory disorder, and intestinal ischemia predominated in patients with other causes of thrombocytopenia [34]. The study also evaluated outcomes in perioperative cardiac surgical patients with clinical suspicion of HIT. Patients found to be antibody-positive were compared with HIT antibody-negative patients. The results showed no significant difference in mortality rates between antibody-positive patients and antibodynegative patients, suggesting that a diagnosis of HIT itself is not as strong a predictor of perioperative mortality as sepsis, age, and female sex [34]. However, all patients with concomitant sepsis and HIT died, underscoring the particular vulnerability of this population.

The goals of treatment for HIT are threefold: Interrupt the pathological immune response, inhibit the uncontrolled generation of thrombin, and minimize the complications. The immune response that leads to HIT is interrupted by the immediate withdrawal of all forms of heparin including subcutaneous injection, IV flushes, and heparin bonded-catheters. Low molecular weight heparin should not be used in these patients due to an approximate risk of $90 \%$ for cross-reactivity with anti-P4/heparin antibodies [29]. Extensive measures must be implemented to label these patients with "heparin allergy" in the chart and at the bedside to avoid accidental exposure to heparin.

Cessation of heparin alone does not sufficiently reduce the risk of thrombosis. The next step in management targets the uncontrolled generation of thrombin with the use of direct thrombin inhibitors (DTIs). The advantage of DTIs is that they bind and inhibit both clotbound and circulating thrombin, thereby reversing the process of HIT rather than simply halting it. In addition, the molecular structure of DTIs prohibits cross-reactivity with anti-P4/heparin antibodies. There are, however, some significant disadvantages to the use of these agents. The inhibition of thrombin by DTIs is an irreversible process with no antidote available to manage possible significant bleeding complications. DTIs must be monitored closely for appropriate dosing, with individual algorithms for each drug. DTIs significantly prolong the International Normalized Ratio (INR), which complicates the process of bridging to oral anticoagulation with warfarin [31]. The INR values that DTIs confer do not conform to the currently established standards used to manage bleeding risk, and special procedures are required to obtain INR levels that reflect warfarin's anticoagulation effect alone.

Lepirudin and argatroban are the two mostly widely studied DTIs for the treatment of HIT in large clinical trials [29]. Lepirudin is a recombinant form of hirudin. It is renally excreted with a half-life of 90 minutes. Argatroban is an L-arginine derivative metabolized by the hepatobiliary system with a half life of approximately 30-50 minutes. Argatroban is preferred in patients with renal insufficiency, whereas lepirudin is the drug of choice for patients with liver disease [27]. A third drug, bivalirudin is the newest DTI approved by the FDA for use in patients undergoing percutaneous coronary intervention, but not for the treatment of HIT in other settings. Bivalirudin is another hirudin analog that differs from lepirudin in that it is hemodialyzable and primarily undergoes enzymatic elimination. Its half-life is the shortest, 20-25 minutes, making bivalirudin the safest option since there are no reversal agents available. Bivalirudin has a particular 
advantage over lepirudin in the setting of surgery. In procedures such as cardiopulmonary bypass where prolonged hypotension leads to acute kidney injury, or abdominal aortic aneurysm repair which occasionally causes damage to the renal vasculature, lepirudin should be avoided due to its dependence on renal clearance. All three agents can be monitored using the activated partial thromboplastin time (aPTT) to levels of 1.5 to 2.0 above baseline [27]. Once the platelet count has increased to a minimum of $150,000 / \mu \mathrm{L}$ bridging therapy to warfarin is essential for the safe transition from DTIs. Initial therapy with warfarin is associated with hypercoagulability due to the initial drop in levels of protein C. In patients with deep vein thrombosis there is an increased risk of venous gangrene due to this effect. Warfarin should be started at low maintenance dosing of $5 \mathrm{mg} /$ day or less for a minimum of 5 days of overlapping therapy with a DTI $[27,31]$. Oral anticoagulation should be maintained for 3 to 6 months regardless of whether thrombosis is present (add reference).

In cardiac surgical patients who have had a previous episode of HIT, the use of heparin is not contraindicated because the immune response is atypical and re-exposure does not trigger a rapid response such as anaphylaxis. The approach to patients with acute or subacute HIT is to delay a cardiac surgical procedure until the episode of HIT has resolved and platelet-activating antibodies are no longer measurable. In patients with active HIT who require urgent cardiac surgery, bivalirudin is considered the best alternative to heparin by the American College of Chest Physicians (ACCP) for both on pump and off-pump procedures27. Bivalirudin's emergence as a DTI with a short half life has placed it near the top of the list for drugs used to manage HIT as well as an alternative to heparin in cardiac surgery. The benefits of this drug lie additionally in its $80 \%$ enzymatic elimination. Furthermore, bivalirudin was shown in 2 clinical trials to be a safe and effective heparin alternative for cardiac surgery patients with HIT, and was additionally applicable clinically to patients with impaired renal function [27]. Currently, bivalirudin is only approved for management of HIT in patients undergoing PCI, however it's off label use is rapidly expanding and in the future it is possible that it will emerge as a contentious rival to heparin for different cardiac surgery procedures.

Other alternative treatments for cardiac patients with preoperative HIT have also been reported. Antoniou et al. investigated the use of intravenous iloprost both pre- and perioperatively in 22 patients with HIT requiring heparin for cardiopulmonary bypass [38]. Iloprost is a prostacyclin analogue that reversibly inhibits platelet aggregation. The study reported a significant reduction in thromboembolic events and preservation of platelet count both peri- and postoperatively. Jaben et al. reported two cases where plasma exchange was used preoperatively to reduce anti-PF4/heparin antibodies in patients with clinical evidence of HIT requiring emergency cardiopulmonary bypass surgery [40]. Plasma exchange was successful in reducing anti-P4/heparin antibodies and allowed for the restoration of a normal platelet count, essentially reversing the disease. Both methods showed promising results, but have not yet been sufficiently studied for optimal use in cardiac surgery.

In today's clinical setting emphasis must be placed on the prevention of HIT. The use of LMWH and heparin analogues such as fondaparinux and danaparoid are associated with lower risk of HIT as compared to unfractionated heparin $[13,25]$. Generally speaking the most effective means of preventing HIT is to limit the duration of the heparin therapy or to use LMWH in place of unfractionated heparin [13]. An additional strategy which is often overlooked is to begin warfarin therapy earlier in patients who will require long term anticoagulation thus minimizing heparin exposure [13].
In conclusion, HIT presents today as an underdiagnosed condition with life threatening thrombotic complications. Patients who have undergone cardiac surgery remain a troublesome group to clinically diagnose due to the natural occurrence of post-operation thrombocytopenia. The 4T's assessment point system was designed in order to evaluate the likelihood a patient has HIT based on the clinical presentation. The AACP recommended guidelines state that when a patient is suspected of having HIT treatment is to be started while awaiting laboratory confirmation. The gold standard for the diagnosis of HIT is the serotonin release assay. Treatment of HIT involves cessation of all heparin administration as well as the use of direct thrombin inhibitors (DTI). Currently, the 2 recommended DTIs for the treatment of HIT are Lepuridin and Argatroban, with the exception of HIT post PCI in which bivaluridin is the first line of treatment. One major drawback of DTIs is a lack of an antidote. Bivaluridin is being heralded as a potential first line drug in all cases of HIT due to its benefits of a short half life and enzymatic elimination.

\section{References}

1. Warkentin TE, Greinacher A, Koster A, Lincoff AM; American College of Chest Physicians (2008) Treatment and prevention of heparin-induced thrombocytopenia: American College of Chest Physicians Evidence-Based Clinical Practice Guidelines (8th Edition). Chest 133: 340S-380S.

2. Stanton PE Jr, Evans JR, Lefemine AA, Vo NM, Rannick GA, et al. (1988) White clot syndrome. South Med J 81: 616-620.

3. Chong BH, Castaldi PA (1986) Platelet proaggregating effect of heparin possible mechanism for non-immune heparin-associated thrombocytopenia. Aust N Z J Med 16: 715-716.

4. Greinacher A (1995) Antigen generation in heparin-associated thrombocytopenia: the nonimmunologic type and the immunologic type are closely linked in their pathogenesis. Semin Thromb Hemost 21: 106-116.

5. Assmann A, Boeken U, Feindt P, Schurr P, Akhyari P, et al. (2010) Heparininduced thrombocytopenia type II after cardiac surgery: predictors and outcome. Thorac Cardiovasc Surg. 58: 463-467

6. Martel N, Lee J, Wells PS (2005) Risk for heparin-induced thrombocytopenia with unfractionated and low-molecular-weight heparin thromboprophylaxis: a meta-analysis. Blood 106: 2710-2715.

7. Warkentin TE, Levine MN, Hirsh J, Horsewood P, Roberts RS, et al. (1995) Heparin-induced thrombocytopenia in patients treated with low-molecularweight heparin or unfractionated heparin. N Engl J Med 332: 1330-1335.

8. Harbrecht $U$, Bastians B, Kredteck A, Hanfland P, Klockgether T, et al (2004) Heparin-induced thrombocytopenia in neurologic disease treated with unfractionated heparin. Neurology 62: 657-659.

9. Girolami B, Prandoni P, Stefani PM, Tanduo C, Sabbion P, et al. (2003) The incidence of heparin-induced thrombocytopenia in hospitalized medical patients treated with subcutaneous unfractionated heparin: a prospective cohort study. Blood 101: 2955-2959.

10. Morris TA, Castrejon S, Devendra G, Gamst AC (2007) No difference in risk for thrombocytopenia during treatment of pulmonary embolism and deep venous thrombosis with either low-molecular-weight heparin or unfractionated heparin a metaanalysis. Chest 132: 1131-1139.

11. Warkentin TE, Sheppard JA, Sigouin CS, Kohlmann T, Eichler P, et al (2006) Gender imbalance and risk factor interactions in heparin-induced thrombocytopenia. Blood 108: 2937-2941.

12. Warkentin TE, Eikelboom JW (2007) Who is (still) getting HIT? Chest 131: 1620-1622.

13. Stein PD, Hull RD, Matta F, Yaekoub AY, Liang J (2009) Incidence of thrombocytopenia in hospitalized patients with venous thromboembolism. Am J Med 122: 919-930.

14. Lubenow N, Hinz P, Thomaschewski S, Lietz T, Vogler M, et al. (2010) The severity of trauma determines the immune response to PF4/heparin and the frequency of heparin-induced thrombocytopenia. Blood 115: 1797-1803.

15. Warkentin TE, Sheppard JA, Horsewood P, Simpson PJ, Moore JC, et al. 
Citation: Steele J, Kadosh B, Gulkarov IM, Salemi A (2011) Heparin Induced Thrombocytopenia and Cardiac Surgery: A Comprehensive Review. J Blood Disord Transfus S2:003. doi:10.4172/2155-9864.S2-003

(2000). Impact of the patient population on the risk for heparin-induced thrombocytopenia. Blood 96: 1703-1708.

16. Bauer TL, Arepally G, Konkle BA, Mestichelli B, Shapiro SS, et al. (1997) Prevalence of heparin-associated antibodies without thrombosis in patients undergoing cardiopulmonary bypass surgery. Circulation 95: 1242-1246.

17. Krauel K, Pötschke C, Weber C, Kessler W, Fürll B, et al. (2011)Platelet factor 4 binds to bacteria-inducing antibodies cross-reacting with the major antigen in heparin-induced thrombocytopenia. Blood 117: 1370-1378.

18. Warkentin, TE, Kelton, JG (1994) Interaction of heparin with platelets, including heparin-induced thrombocytopenia. Fundamental and Clinical Cardiology, Marcel Decker, New York

19. Warkentin TE (1998) Clinical presentation of heparin-induced thrombocytopenia Semin Hematol 35: 9-16.

20. Nader ND, Khadra WZ, Reich NT, Bacon DR, Salerno TA, et al. (1999) Blood product use in cardiac revascularization: comparison of on- and off-pump techniques. Ann Thorac Surg 68: 1640-1643.

21. Selleng S, Malowsky B, Strobel U, Wessel A, Ittermann T, et al. (2010) Earlyonset and persisting thrombocytopenia in post-cardiac surgery patients is rarely due to heparin-induced thrombocytopenia, even when antibody tests are positive. J Thromb Haemost 8: 30-36.

22. Gruel Y, Pouplard C (2010) Post-operative platelet count profile: the most reliable tool for identifying patients with true heparin-induced thrombocypenia after cardiac surgery. J Thromb Haemost 8: 27-29.

23. Szokol JW (2010) Heparin-induced thrombocytopenia. Semin Cardiothorac Vasc Anesth 14: 73-74

24. Demma LJ, Levy JH (2011) Diagnosing heparin-induced thrombocytopenia in cardiac surgical patients: not as easy as you think. Anesth Analg 112: 747-749.

25. Gruel Y, Pouplard C, Nguyen P, Borg JY, Derlon A, et al. (2003) Biological and clinical features of low-molecular-weight heparin-induced thrombocytopenia. $\mathrm{Br}$ J Haematol 121:786-792.

26. Rezende E, Morais G, Silva Junior JM, de Oliveira AM, Souza JM, et al. (2011) Thrombocytopenia in cardiac surgery: diagnostic and prognostic importance. Rev Bras Cir Cardiovasc 26: 47-53.

27. Augoustides JG (2011) Update in hematology: heparin-induced thrombocytopenia and bivalirudin. J Cardiothorac Vasc Anesth 25: 371-375.

28. Kigawa I, Okamura Y, Fukuda S, Miyairi T (2010) Heparin-induced thrombocytopenia after on-pump coronary artery bypass grafting. Kyobu Geka 63: $442-445$
29. Hong MS, Amanullah AM (2010) Heparin-induced thrombocytopenia: a practical review. Rev Cardiovasc Med 11: 13-25.

30. Walls JT, Boley TM, Curtis JJ, Silver D (1992) Heparin induced thrombocytopenia in patients undergoing intra-aortic balloon pumping after open heart surgery. ASAIO J 38: M574-M576.

31. Koster A, Kukucka M (2004) Anticoagulation of patients with heparin-induced thrombocytopenia in cardiac surgery. Curr Opin Anaesthesiol 17: 71-74.

32. Ali N, Moiz B, Rehman Y, Salman M, Sami SA (2009) The frequency of heparin induced thrombocytopenia in patients undergoing elective cardiac bypass surgeries. J Pak Med Assoc 59: 345-350.

33. Matsue H, Masai T, Yoshikawa Y, Kawamura M (2010) Serious acute coronary thrombosis associated with heparin-induced thrombocytopenia in off-pump coronary artery bypass grafting. Interact Cardiovasc Thorac Surg 11: 188-190.

34. Thielmann M, Bunschkowski M, Tossios P, Selleng S, Marggraf G, et al. (2010) Perioperative thrombocytopenia in cardiac surgical patients - incidence of heparin-induced thrombocytopenia, morbidities and mortality. Eur $J$ Cardiothorac Surg 37: 1391-1395.

35. Herman K, Vaszily M, Szentgyörgyi L, Ajzner E, Muszbek L, et al. (2008) Anticoagulation with hirudin for repeat cardiac surgery in a patient with heparin induced thrombocytopaenia. Magy Seb 61: 67-70.

36. Wheatcroft MD, Greco E, Tse L, Roche-Nagle G (2011) heparin-induced thrombocytopenia in the presence of a heparin-bonded bypass graft. Vascular [Epub ahead of print]

37. Haneya A, Philipp A, Lehle K, Diez C, Rupprecht L, et al. (2011) Successful use of hirudin during cardiac surgery using minimized extracorporeal circulation in patients with heparin-induced thrombocytopenia. Thoracic Surg 92: 724-726.

38. Antoniou T, Kapetanakis El, Theodoraki K, Rellia P, Thanopoulos A, et al (2002) Cardiac surgery in patients with heparin-induced thrombocytopenia using preoperatively determined dosages of iloprost. Heart Surg Forum 5: 354 357

39. Walls JT, Boley TM, Curtis JJ, Silver D (1992) Heparin induced thrombocytopenia in patients undergoing intra-aortic balloon pumping after open heart surgery. ASAIO J 38: M574-576.

40. Jaben EA, Torloni AS, Pruthi RK, Winters JL (2011) Use of plasma exchange in patients with heparin-induced thrombocytopenia: A report of two cases and a review of the literature. J Clin Apher 26: 219-224. 